\section{SOI: $1.1 /$ TAS DOI: $10.15863 / \mathrm{TAS}$ \\ International Scientific Journal Theoretical \& Applied Science}

\author{
p-ISSN: 2308-4944 (print) e-ISSN: 2409-0085 (online) \\ Year: $2016 \quad$ Issue: 1 Volume: 33 \\ Published: $30.01 .2016 \quad$ http://T-Science.org
}

\begin{abstract}
Rezvan Torabi
Assistance Professor in Islamic Azad University, Dehaghan Branch, Department of finance,

Esfahan, Iran

torabi.economic@gmail.com
\end{abstract}

Mehrdad Farshid

Master of finance in Islamic Azad University, Dehaghan Branch, Department of finance,

Esfahan, Iran

SECTION 31. Economic research, finance, innovation, risk management.

\title{
THE EFFECT OF CORPORATE GOVERNANCE AND AUDIT EXPERT ON PREDICTION ACCURACY OF SHARES RETURN IN SELECTED INDUSTRY IN TEHRAN STOCK EXCHANGE
}

\begin{abstract}
The important role of financial accounting and corporate governance is to help financial users about forming their expectations related to companies' future interest. Previous studies have shown financial accountant experts in audit committee have relationship with high quality of financial reporting in companies. The aim of this research is to study the effect of corporate governance and professional auditor on accuracy of predicting the shares return in selected industries listed in Tehran Stock Exchange during 2006 to 2013. The results of research show that corporate governance indexes on the amount of first estimation remains as accuracy of predicting shares return variable as dependent variable in second pattern is significant and it indicates that the effect of the percent of biggest ownership on dependent variable of predicting shares return error is negative and significant, it is recommended that to reduce predicting shares return error and as a result increasing the accuracy of predicting shares return, financial managements of Tehran Stock Exchange companies must apply policies based on increasing the percent of biggest shares ownership. The effect of corporate governance variable on dependent variable of error of predicting shares return is negative and significant and it is recommended to reduce error of predicting shares return and as a result increasing the accuracy of predicting shares return, financial managements of Tehran Stock Exchange companies should apply based on increasing the percent of shares governance ownership.

Key words: corporate governance, expert auditor, predicting shares return.

Language: English

Citation: Torabi R, Farshid M (2016) THE EFFECT OF CORPORATE GOVERNANCE AND AUDIT EXPERT ON PREDICTION ACCURACY OF SHARES RETURN IN SELECTED INDUSTRY IN TEHRAN STOCK EXCHANGE. ISJ Theoretical \& Applied Science, 01 (33): 11-17.

Soi: http://s-o-i.org/1.1/TAS-01-33-3 Doi: crossef http://dx.doi.org/10.15863/TAS.2016.01.33.3
\end{abstract}

\section{1- Introduction}

Discussion of corporate governance is great importance after the recent financial crisis. The role of corporate governance is important for several reasons. First of all, the establishment of corporate governance causes to use scarce resources in economic efficiently. Secondly, resources allocate toward efficient investments. Thirdly, corporate governance helps management to concentrate on improving firms' performance. Fourthly, corporate governance helps managing director or the board of management to select best tool to control scarce resources. Fifthly, corporate governance forces institutions to accept rules.

Based on this theory, delegation relationship is the contract between shareholders and the management of financial institution. Based on delegation theory, the board of directors ignores the management of shareholders for controlling the management of the firms. Therefore, the board of directors shows reaction directly to control company appropriately. Therefore, bad selection and moral hazard might be happened due to separating management from ownership and the board of management might maximize their interests against shareholders interests. Therefore, the mechanism should be applied to consider the shareholders' interests. Making suitable corporate governance can remove interest differences.

The role of auditing in accreditation to the information of companies' interest about renewing presenting recent company's interest and big companies' bankruptcy is important considerably. The differences caused by auditing quality show 
themselves as the difference in presented validity by auditors and interest quality of their clients. Since auditing quality has different criteria and it is invisible inherently, there is no any especial auditing which is considered as the index for it. Most of previous researches use auditor's reputation as the index for auditing quality and have studied the relationship between reputation and interest quality. In addition, other researchers in addition to reputation express their assumption in a way that auditor industry specialization help the presented validity by auditor directly and the evidences indicate that especial auditor of industry presents more effectiveness auditing and structural changes in auditing companies toward accessing to industry specialization indicate that industry specialization plays important role in auditing quality.

The purpose of this research is to study the effect of corporate governance and professional auditor on the accuracy of predicting shares return in selected industries listed in Tehran Stock Exchange during the period of 2006 to 2013.

\section{2- Theoretical framework}

\section{2-1-Corporate governance}

For many years in the past, economists assume that all groups related to one shares company work for one common goal. However, in past thirty years many cases from conflicts of interest between groups and the way companies face to these conflicts have posed by economists. These issues are posed generally under the title of delegation theory in accounting. The relationship of delegation is contract which owner of work or owner selects agent by itself and concedes decision-making to them. In delegation relationships, the aim of owner is maximizing wealth and therefore, to access to this goal, they control the agents' work and they evaluate their performance.

Managements' activities are limited or guided by some factors. These factors should be posed for more suitable corporate governance and companies consider rules and requirements in doing their duties and different institutions monitor on the benefit of activities of economic units. These factors contain many cases such as: board of management (The right to hire and fire and reward their managers), rules, worker agreements, market and even competition environment. Generally, the factors in above can be considered in two forms of external control mechanisms (like market) and internal control mechanisms (like board of management) (Karami, 2008).

One of the effective external control mechanisms on corporate governance which is very important is the emergence of institutional investors as the owner of capital. Based on Boosch definition
(1998), institutional investors are big investors like banks, insurance companies, investment companies and etc. he expressed that institutional investors concede companies through collecting information and pricing management decisions implicitly and through controlling the way of companies' acts correctly. In better words, institutional investors have resources to influence and control management and also whether institutional investors use their power to control or not, are the function of the amount of their ownerships (Chang and Kim, 2002).

\section{2-2- $\quad$ Auditing quality}

Although the auditor responsibilities in auditing quality are accepted as one of the auditing behavioral assumptions (Hasas Yegane, 2005), however, far less comprehensive and clear definition of audit quality that is acceptable to everyone has done. Perhaps, this situation can be justified with regard to the issue that auditors responsibilities in each period of time is describable in the form of public expectations, and also with regard to the issue that auditing quality is a concept which cannot observe directly (Lin et al, 2009).

\section{2-3- $\quad$ Auditor expertise in the industry}

Auditors can create a kind of difference between themselves and other auditors due to the reason that they are looking forward to obtain expertise in handling active companies in the industry. The existence of this differentiation gives possibility to auditors to have two options of less price and high services quality (better disclosure quality) simultaneously instead of having one attractive option (less price for auditing) to attract the shareholders of public societies (Kimberly et al, 2004: 39).

\section{2-4- $\quad$ Research background}

Abernati et al (2013) in an article entitled "the committee of financial auditing specialization and the characteristics of predicting interest by analyzers" have been dealt with to study this issue. The main findings of this study show that there is significant relationship between financial accounting specializations in auditing committee and predicting interest which is done by analyzers. In contrast, there is no any significant relationship between nonfinancial accounting specializations (like controlling specializations) and the accuracy of prediction which is done by analyzers. these findings has dealt with better understanding the relationship between these two cases through determining the advantages of entering financial specializations in auditing committee.

Almensir et al (2012) in an article entitled "the effect of corporate governance on the performance of banks of Jordan" have studied this issue. The indexes 
of the board of management size, the combination of the board of management and external ownership consider as corporate governance indexes. The obtained results indicate that there is positive relationship between corporate governance indexes those mean the number of the board of management members and external ownership and the performance of banking system of Jordan. The board of management size and separating ownership from management has negative relationship with the performance of banking system of this country.

Peni et al (2012) in their article examined the effect of corporate governance of banks on giving credit to deposit sector and the amount of doubtful receivable during the period of financial crisis. The results indicate that banks those have stronger corporate governance mechanisms to compare with other banks, their profitability indexes are also higher. Also, the effect of corporate governance on giving credits in deposit sector has been complex and it depends on the definition of crisis period. Although, banks those have stronger corporate governance to compare with others experience less amount of doubtful receivable. Banks with weaker corporate governance after the issue that deposit market reach to crisis, they reduce the deposit loans those are in danger.

Tie (2011) has studied the effect of corporate governance on profitability of banks by theory agency and the statistics of 15 banks in the country of Malaysia. The indexes of return asset and shares return are considered as the indexes of profitability of banks. The estimated results indicate that independency of the board of directors and the kind of bank ownership has negative relationship with shares return.

Karjalinen (2011) found that expertise in auditing partner industry in Finland has positive relationship with the quality of reported interest. He observed that the level of discretionary accruals in companies those are auditing by expertise partner is less than private companies. Therefore, the results indicate this claim that the expertise of auditing partner industry of one resource considers as differentiate in auditing quality.

\section{3- Research pattern}

Based on research and theoretical literature, the econometric model in below is used in this research:

\section{Dependent variable: DASP}

The accuracy of predicting shares return which is obtained by the difference of real amount and the amount of shares return estimation (the amount of estimation remains)

$$
\begin{aligned}
Y=\alpha_{0}+\alpha_{1} \text { Coverge } & +\alpha_{2} \text { So }+\alpha_{3} \text { Size }+\alpha_{4} \text { EL } \\
& +\alpha_{5} \text { ROA }+\alpha_{6} \text { DPS }+\alpha_{7} \text { Loss } \\
& +\alpha_{8} \text { industries dummies } \\
& +\alpha_{9} \text { year }+\varepsilon
\end{aligned}
$$

In first equation, $\mathrm{Y}$ is the variable of shares return of the company.

Then, with the use of extracting the amount of estimation remains as the variable of accuracy of predicting shares return, this variable is used in the second pattern as dependent variable and the pattern in below is estimated:

$$
\begin{aligned}
& \text { DASP }=\alpha_{0}+\alpha_{1} \text { Coverge }+\alpha_{2} \text { So }+\alpha_{3} \text { Size }+\alpha_{4} \text { EL } \\
&+\alpha_{5} \text { ROA }+\alpha_{6} D P S+\alpha_{7} \text { Loss } \\
&+\alpha_{8} \text { industries dummies } \\
&+\alpha_{9} \text { year }+\varepsilon
\end{aligned}
$$

Independent variable:

The indexes of corporate governance: the total member of the board of management, the number of non-responsibilities, dual responsibilities of CEO.

Specialist virtual variable auditor so: according to the issue that the expertise of auditor in different companies is different, in this research the virtual variable of zero and 1 to exist the expert, there are varieties of auditors depend on kind of expertise contain: financial accounting, financial nonaccounting and non-financial in auditing committee.

\section{Control variables:}

Company size (asset logarithm) Size, the ratio of debt to total asset EL, profitability index ROA, the index of interest of each share DPS, the index of company loss.

\section{4- Model estimation}

Based on the results of F Limer test and Hasman test, the model of research is estimated based on panel data method by fix effects. The amount of $\mathrm{F}$ regression which shows the power of model explanation is less than $0 / 01$ for this statistical probability and it can be said that it is significant in confidence level of 99 percent and it is authentic. Also, observing the amount of Durbin-Watson statistic (1/84) is also confirmed the issue that there is no any disruption autocorrelation between components, because this amount is between $1 / 5$ and $2 / 5$. 


\begin{tabular}{|c|c|c|c|c|c|c|}
\hline Impact Factor: & $\begin{array}{l}\text { ISRA (India) } \\
\text { ISI (Dubai, UAE } \\
\text { GIF (Australia) } \\
\text { JIF }\end{array}$ & $\begin{array}{l}=1.344 \\
=0.829 \\
=0.564 \\
=1.500\end{array}$ & $\begin{array}{l}\text { SIS (USA) } \\
\text { PUHЦ (Russia } \\
\text { ESJI (KZ) } \\
\text { SJIF (Morocce }\end{array}$ & $\begin{array}{l}=0.912 \\
=0.179 \\
=1.042 \\
=2.031\end{array}$ & $\begin{array}{l}\text { ICV (Poland) } \\
\text { PIF (India) }\end{array}$ & $\begin{array}{l}=6.630 \\
=1.940\end{array}$ \\
\hline
\end{tabular}

Table 1

The results related to estimating the fix effects of research model (dependent variable: DASP (the error of predicting shares return)).

\begin{tabular}{|c|c|c|c|c|c|}
\hline p_Value & Statistic t & $\begin{array}{l}\text { The error } \\
\text { of } \\
\text { standard }\end{array}$ & $\begin{array}{l}\text { Estimate } \\
\text { coefficient }\end{array}$ & $\begin{array}{l}\text { Variable } \\
\text { symbol }\end{array}$ & The name of variable \\
\hline 0.0001 & 4.071384 & 4.010627 & 16.32880 & $\mathrm{C}$ & Intercept \\
\hline 0.0612 & 1.880734 & 0.047652 & 0.089621 & $\mathrm{X} 1$ & $\begin{array}{l}\text { Indexes of corporate governance (total } \\
\text { member of the board of managements) }\end{array}$ \\
\hline 0.0909 & 2.311641 & 0.031313 & 0.041072 & $\mathrm{X} 2$ & $\begin{array}{l}\text { Indexes of corporate governance } \\
\text { (number of non-responsibilities) }\end{array}$ \\
\hline 0.0141 & 2.471893 & 0.082968 & 0.205087 & $\mathrm{X} 3$ & $\begin{array}{l}\text { Indexes of corporate governance (dual } \\
\text { responsibilities of CEO) }\end{array}$ \\
\hline 0.0200 & -2.342829 & 0.116207 & -0.272253 & $\mathrm{X} 4$ & $\begin{array}{c}\text { Virtual variable of specialist auditor } \\
\text { (audit quality) }\end{array}$ \\
\hline 0.0242 & -2.637786 & 0.473766 & -0.302161 & $\mathrm{X} 5$ & $\begin{array}{c}\text { The ratio of debt to total asset(financial } \\
\text { leverage) }\end{array}$ \\
\hline 0.0117 & -2.539469 & 0.474749 & -1.205611 & $\mathrm{X} 6$ & Profitability index (ROA) \\
\hline 0.0000 & -4.395791 & 0.617962 & -2.716432 & $\mathrm{X} 7$ & Company size(asset logarithm) \\
\hline 0.0195 & 2.228486 & 0.357389 & 0.181658 & $\mathrm{X} 8$ & Company loss index (Loss) \\
\hline 0.0000 & -6.633814 & 0.375717 & -2.492437 & $\mathrm{X} 10$ & $\begin{array}{l}\text { The index of the interest of each share } \\
\text { DPS (working capital/ assets) }\end{array}$ \\
\hline 0.569532 & $\begin{array}{l}\text { Determine } \\
\text { coefficient }\end{array}$ & 0.000000 & $\begin{array}{l}\text { Significance } \\
\text { of F statistic }\end{array}$ & & $4.506050:$ F statistics \\
\hline 0.357615 & $\begin{array}{l}\text { Adjusted } \\
\text { determine } \\
\text { coefficient }\end{array}$ & 305 & $\begin{array}{c}\text { The number } \\
\text { of } \\
\text { observations }\end{array}$ & 1.846655 & Durbin-Watson test \\
\hline
\end{tabular}

The results of model show that the effect of indexes of corporate governance on dependent variable of DASP (the error of predicting shares return) is significant end it indicates that the effect of total member of the board of management variable on dependent variable of DASP (the error of predicting shares return)in amount of $0 / 089621$ is positive and significant and also the effect of corporate governance variable (the number of nonresponsibilities) on dependent variable of DASP (the error of predicting shares return)in amount of 0/041072 is positive and in the level of 10 percent is significant. The effect of corporate governance indexes variable (dual responsibilities of the board of management) on dependent variable of DASP in amount of $0 / 205087$ is positive and in the level of 10 percent is significant. This shows that increasing the number of management in the board of directors creates kind of information asymmetric for shares that in light of this lack of transparency and a possible bribery, the risk and fluctuation of the company will eb increased and the error of predicting shares return will be increased and consequently, the accuracy of predicting shares return will be reduced.

The results of research also indicate that the effect virtual independent variable specialist auditor on dependent variable of DASP in amount of $0 / 272253$ is negative and significant and it shows that with the existence of varieties of auditors depends on kind of specialist contains financial accounting, financial non-accounting and nonfinancial in auditing committee, the probability of lack of information asymmetric for shares will be decreased that in the light of increasing auditing quality and transparency, risk and fluctuation of company will be reduced and the error of predicting shares return will be reduced and consequently, the accuracy predicting shares return will be increased.

The results of research also indicate that the effect of controlling variable of company size (assets logarithm) on dependent variable of DASP (the error of predicting shares return) in amount of 2/716432 is negative and significant and it shows with the existence of increasing company's assets, size and credit of the company will be increased that in the light of increasing this credit, risk and fluctuation of company is decreased and the error of predicting shares return is decreased and consequently, the accuracy of predicting shares return will be increased.

The results of research also indicate that the effect of controlling variable of the ration of debt to total asset (financial leverage) on dependent variable of DASP (the error of predicting shares return) in amount of $0 / 302161$ is negative and significant and it 
shows that with the existence of financial leverages of company, risk of bankruptcy of the company will be increased that in the light of increasing this, risk and fluctuation of company is increased and the error of predicting shares return is increased and consequently, the accuracy of predicting shares return will be decreased.

The results of research also indicate that the effect of controlling variable of profitability index ROA on dependent variable of DASP (the error of predicting shares return) in amount of $1 / 205611$ is negative and significant and it shows that with the existence of increasing profitability index ROA, size and credit and persuading shareholders to company will be increased that in the light of increasing this credit, risk and fluctuation of the company will be decreased and the error of predicting shares return will be decreased and consequently, the accuracy of predicting shares return will be increased.

The results of research indicate that the effect of controlling variable of index of interest of each share DPS on dependent variable of DASP in amount of 2/492437 is negative and significant and it shows that with the existence of increasing the index of interest of each share DPS, size and credit and persuading shareholders to company will be increased that in the light of increasing this credit, risk and fluctuation of the company will be decreased and the error of predicting shares return will be decreased and consequently, the accuracy of predicting shares return will be increased.

The results also indicate that the effect of controlling variable of company loss index on dependent variable of DASP in amount of 0/181658 is positive and significant and it shows that with the existence of increasing company loss index, credit and persuading shareholders to company will be decreased that in the light of reducing this credit, risk and fluctuation of the company will be increased and the error of predicting shares return will be increased and consequently, the accuracy of predicting shares return will be decreased.

\section{5- Conclusion and Recommendations}

- According to the results, second model of research shows that the effect of corporate governance indexes Coverge on amount of remains of first estimation as the accuracy of predicting shares return variable as dependent variable in second pattern are significant and it indicates that the effect of the percent of biggest ownership on dependent variable of the error of predicting shares return is negative and significant, it is recommended that to reduce the error of predicting shares return and consequently, increasing the accuracy of predicting shares return, the financial managements of companies listed in Tehran Stock Exchange apply policy based on increasing the percentage of biggest shares ownership.

- Also according to the results of research which show the effect of the government ownership percentage variable on dependent variable of the error of predicting shares return is negative and significant and it is recommended to reduce the error of predicting shares return and consequently, increasing the accuracy of predicting shares return, the financial managements of companies listed in Tehran Stock Exchange apply policies based on increasing governmental shares ownership percentage.

- Also according to the results of research which show the effect of independent variable of institutional ownership percentage on dependent variable of the error of predicting shares return is negative and significant, it is recommended to reduce the error of predicting shares return and consequently, increasing the accuracy of predicting shares return, the financial managements of companies listed in Tehran Stock Exchange apply policies based on increasing the shares institutional ownership percentage.

- Also according to the results of research which show the effect of independent variable of managers ownership percentage on dependent variable of the error of predicting shares return is positive and significant, it is recommended to reduce the error of predicting shares return and consequently, increasing the accuracy of predicting shares return, the financial managements of companies listed in Tehran Stock Exchange apply policies based on reducing the shares managers ownership percentage.

- Also according to the results of research which show the effect of independent variable of the number of managers in the board of directors on dependent variable of the error of predicting shares return is positive and significant, it is recommended to reduce the error of predicting shares return and consequently, increasing the accuracy of predicting shares return, the financial managements of companies listed in Tehran Stock Exchange apply policies based on reducing the number of managers in the board of directors.

- Also according to the results of research indicate that the effect of independent variable of virtual variable of specialist auditor on dependent variable of the error of predicting shares return is negative and significant, it is recommended to reduce the error of predicting 


\begin{tabular}{l|lrl|l|ll} 
& ISRA (India) & $=\mathbf{1 . 3 4 4}$ & SIS (USA) & $=\mathbf{0 . 9 1 2}$ & ICV (Poland) & $=\mathbf{6 . 6 3 0}$ \\
Impact Factor: & ISI (Dubai, UAE) $=\mathbf{0 . 8 2 9}$ & PUHL (Russia) $=\mathbf{0 . 1 7 9}$ & PIF (India) & $=\mathbf{1 . 9 4 0}$ \\
& GIF (Australia) & $\mathbf{0 . 5 6 4}$ & ESJI (KZ) & $=1.042$ & & \\
& JIF & $\mathbf{1 . 5 0 0}$ & SJIF (Morocco) $=\mathbf{2 . 0 3 1}$ & &
\end{tabular}

shares return and consequently, increasing the accuracy of predicting shares return, the financial managements of companies listed in Tehran Stock Exchange apply policies based on increasing the number of shares specialist auditor.

- Also according to the results of research which show the effect of controlling variable of company size (asset logarithm) on dependent variable of the error of predicting shares return is negative and significant, it is recommended to reduce the error of predicting shares return and consequently, increasing the accuracy of predicting shares return, the financial managements of companies listed in Tehran Stock Exchange apply policies based on increasing shares company size (asset logarithm).

Also according to the results of research which show the effect controlling variable of the ratio of debt to total asset EL on dependent variable of the error of predicting shares return is negative and significant, it is recommended to reduce the error of predicting shares return and consequently, increasing the accuracy of predicting shares return, the financial managements of companies listed in Tehran Stock Exchange apply policies based on reducing shares the ratio of debt to total asset.

Also according to the results of research which show the effect of controlling variable of profitability index ROA on dependent variable of the error of predicting shares return is negative and significant, it is recommended to reduce the error of predicting shares return and consequently, increasing the accuracy of predicting shares return, the financial managements of companies listed in Tehran Stock Exchange apply policies based on increasing the shares profitability index.

- Also according to the results of research which show the effect of controlling variable of interest index of each share DPS on dependent variable of the error of predicting shares return is negative and significant, it is recommended to reduce the error of predicting shares return and consequently, increasing the accuracy of predicting shares return, the financial managements of companies listed in Tehran Stock Exchange apply policies based on increasing the shares interest index of each share.

- Also according to the results of research which show the effect of controlling variable of company loss index on dependent variable of the error of predicting shares return is positive and significant, it is recommended to reduce the error of predicting shares return and consequently, increasing the accuracy of predicting shares return, the financial managements of companies listed in Tehran Stock Exchange apply policies based on reducing the shares company loss index.

\section{References:}

1. Bill Francis, Iftekhar Hasan, Liang Song, Maya Waisman (2013) "Corporate governance and investment-cash flow sensitivity: Evidence from emerging markets", Emerging Markets Review, No. 15 (2013), pp.57-71.

2. Chie Aoyagi, Giovanni Ganelli (2014) "Unstash the Cash! Corporate Governance Reform in Japan Prepared by Chie Aoyagi and Giovanni Ganelli", IMF Working Paper Asia and Pacific Department.

3. Davidson WN, III Xie B, Xu W (2004) Market reaction to voluntary announcements of audit committee appointments: The effect of financial expertise. Journal of Accounting and Public Policy, 23(July), 279-293.

4. Dechow P, Dichev ID (2002) The quality of accruals and earnings: The role of accrual estimation errors. The Accounting Review, 77(Supplement), 35-59.
5. DeFond ML, Hann RN, Hu X (2005) Does the market value financial expertise on audit committees of boards of directors? Journal of Accounting Research, 43(2), 153-193.

6. Dhaliwal D, Naiker V, Navissi F (2010) The association between accruals quality and the characteristics of accounting experts and mix of expertise on audit committees. Contemporary Accounting Research, 27(Fall), 787-827.

7. Dickins D, Hillison W, Platau S (2009) Do financial statement users care about differences in board members' source of financial expertise? Views of financial analysts. The Journal of Applied Business and Economics, 9(2), 21-36.

8. Eames M, Glover S (2003) Earnings predictability and the directing of analysts' earnings forecast errors. The Accounting Review, 78(July), 707-724. 


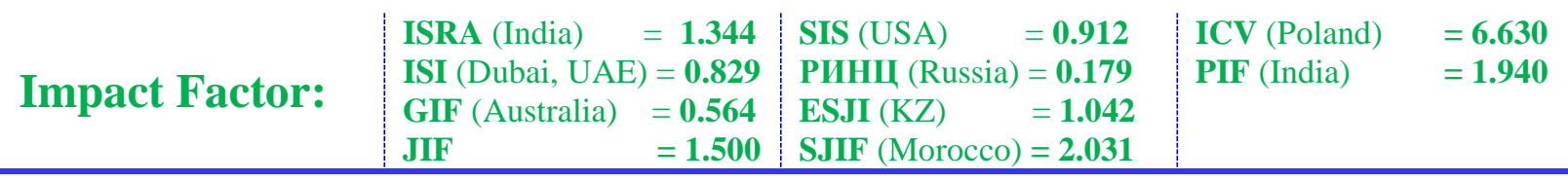

9. Engel E (2005) Discussion of Does the market value financial expertise on audit committees of boards of directors? Journal of Accounting Research, 43(2), 195-204.

10. Farber D (2005) Restoring trust after fraud: Does corporate governance matter? The Accounting Review, 80(2), 539-561.

11. John L Abernathy, Don Herrmann, Tony Kang, Gopal V Krishnan (2013) "Audit committee financial expertise and properties of analyst earnings forecasts", Advances in Accounting, incorporating Advances in
International Accounting, No. 29 (2013), pp. 111.

12. Laurent Frésard, Carolina Salva (2010) "The value of excess cash and corporate governance: Evidence from U.S. cross-listings", Journal of Financial Economics, Vol. 98, Issue 2, November 2010, pp. 359-384.

13. Sabri Boubaker, Imen Derouiche, Walid Saffar (2013) "Excess Control Rights, Corporate Governance and Cash Flow Sensitivity of Cash", Journal of Banking and Finance, No.35, pp.118-129. 